\title{
Periorbital Hyperpigmentation: Overcoming the Challenges in the Management
}

\author{
Agrawal S \\ Professor, Department of Dermatology and Venereology, B.P. Koirala Institute of Health Sciences, Nepal
}

\begin{abstract}
Periorbital hyperpigmentation, also referring as dark circles or periorbital melanosis, is not a medical problem but can be a significant cosmetic concern for a large number of individuals and they try to find a treatment for this condition. This condition affects individuals in a wide range of ages, both sexes and all races. The therapeutic approach must vary with cause as it is multifactorial. Possible causes include excessive pigmentation, volume loss, skin laxity, tear trough, increased prominence and density of subcutaneous vasculature and orbital structural problem. Treatment modalities include topical bleaching agents, chemical peeling, and lasers, injectable fillers, fat transfer, high intensity focused ultrasound and surgery as monotherapy or in combination therapy to target the contributing factors of periorbital hyperpigmentation.
\end{abstract}

Key words: Bleaching agents; chemexfoliation; hyperpigmentation; melanosis; reactive oxygen species

\section{Introduction}

$\mathrm{P}$ eriorbital hyperpigmentation $(\mathrm{POH})$ is a common dermatological condition, which is also known as periorbital melanosis, periocular hyperpigmentation, dark circles under the eyes (DC), infraorbital discoloration, infraorbital darkening, or idiopathic cutaneous hyperchromia of the orbital region. ${ }^{1,2}$ It presents as bilateral, homogeneous hyperchromic macules and patches primarily involving the lower eyelids but also sometimes extending towards the upper eyelids, eyebrows, malar regions, temporal regions and lateral nasal root. ${ }^{3}$ This condition affects individuals with a wide range of age, both sexes and all races. ${ }^{4}$ The age of onset is usually after puberty or in early adulthood (16-25 years). Females are frequently affected by $\mathrm{POH}$ because of either of the two reasons:1) More cosmetically concern and 2) Greater dermal vessels congestion and stasis related extravasation during menstrual cycles.

$\mathrm{POH}$ is a condition that does not cause morbidity but it makes the individuals look tired, sad, or hung over. ${ }^{1}$ There is popular demand for treatment of $\mathrm{POH}$ which is judged by the amount of advertising of cosmetics

Address of Correspondence:

Prof. Sudha Agrawal, MD; M. Phil

Department of Dermatology \& Venereology

B.P. Koirala Institute of Health Sciences

Dharan, Nepal

E-mail:sudha92@yahoo.com marketed to treat this condition. It is a cosmetic concern for a large number of individuals especially women who are really bothered and concerned about it and relating it with significant impairment on their quality of life. ${ }^{5}$ Concealing the lesions is almost mandatory for some individuals who depend on a well-cared and positive appearance for their work or social activities. ${ }^{3}$

Despite patients with $\mathrm{POH}$ often seen by the dermatologists, there is not much attention received in the dermatology literature. There are only a few published studies on its prevalence, causes, pathogenesis and evidence-based treatment modalities. The aim of the review is to highlight the clinical approach to a case of $\mathrm{POH}$ for the management.

Submitted: $15^{\text {th }}$ February 2018

Accepted: $5^{\text {th }}$ March 2018

Published: $21^{\text {st }}$ March 2018

How to cite this article

Agrawal S. Periorbital hyperpigmentation: Overcoming the challenges in the management. Nepal Journal of Dermatology Venereology and Leprology. 2018;16(1):2-11. doi: http://dx.doi. org/10.3126/njdvl.v16i1.19411

Licensed under CC BY 4.0 International License which permits use, distribution and reproduction in any medium, provided the original work is properly cited. 


\section{Etiology}

Periorbital hyperpigmentation is a multi-factorial entity. The pathogenesis of $\mathrm{POH}$ remains elusive. Various exogenous and endogenous factors are possibly concerned in its pathogenesis. The proposed possible causative factors include genetic or heredity, excessive pigmentation, periorbital edema, thin and translucent lower eyelid skin, venous congestion with hemosiderin deposition, orbital structural problem and shadowing due to skin laxity \& tear trough. Other factors such as underlying systemic, metabolic, hormonal diseases, nutritional deficiencies, drugs, allergic reactions, atopic dermatitis, sleep disorders, stress, alcohol consumption, smoking, frequent cosmetic use, frequent eye rubbing and lack of correction for errors of refraction like myopia are also implicated to $\mathrm{POH}^{6}$

\section{Genetic}

Periorbital hyperpigmentation is considered to have a genetic basis. ${ }^{2}$ It is more distinct in Mediterranean ethnic group and is also often seen in multiple members of the same family. ${ }^{3}$

\section{Excessive pigmentation}

Excessive pigmentation is seen in $\mathrm{POH}$ because of dermal melanocytosis and post inflammatory hyperpigmentation secondary to atopic dermatitis or allergic contact dermatitis. In allergic individuals (atopic and allergic contact dermatitis) frequent causes are due to rubbing or scratching the skin around the eyes and accumulation of fluid due to facial allergy. ${ }^{3}$ Excessive pigmentation can also be due to post inflammatory hyperpigmentation secondary to other dermatological conditions (e.g., lichen planus pigmentosus) and can be drug induced. ${ }^{7}$ According to Gathers $^{8}$ chronic use of a few drugs such as hormone-replacement therapy, oral contraceptives, antipsychotics, chemotherapeutic compounds, gold can cause periorbital hyperpigmentation.

Dermal melanocytosis can be due to congenital and environmental causes, which is histologically characterized by the presence of melanocytes in the dermis. Clinically, these lesions are identifiable by the distinctive grey or blue-grey appearance. ${ }^{2}$ Nevus Ota if infraorbitally located, it can be a cause of periorbital hyperpigmentation. ${ }^{1}$ Similarly, nevus of Hori may extend to involve the periocular area, causing $\mathrm{POH} .^{2}$ Environmental causes that result in dermal melanocytosis include excessive sun exposure and drug ingestion. ${ }^{1}$

\section{Periorbital edema}

The eyelid region appears to have a 'sponge' property, which can help in the accumulation of fluid in systemic or local edema causes. An eyelid fluid deposit is characterized by its worsening in the morning or after a salty meal, the purplish color, and the undefined outlines of the regional fat complements. ${ }^{9}$

Minimal subcutaneous fat, thin skin and superficial location of vasculature

Another important cause of $\mathrm{POH}$ may be due to the minimal infraorbital subcutaneous fat, superficial location of the orbicularis oculi muscle, and thin, translucent skin of the lower eyelid. This may lead to a violaceous appearance due to the visible prominence of the subcutaneous vascular plexus or vasculature contained within the muscle. ${ }^{10}$ It is more prominent in the inner aspect of the lower eyelids and is usually accentuated during episodes of physical and mental stress including menstrual period and pregnancy and thus may worsen periorbital hyperpigmentation. ${ }^{1}$

\section{Orbital structural problem}

Advancing age related anatomic changes of the midface soft tissue include subcutaneous fat atrophy and volume loss, hypertrophy of orbicularis oculi muscle, pseudoherniation of suborbicularis oculi fibroadipose tissue and volume loss in the malar region. These features further the appearance of the $\mathrm{POH}$.

\section{Skin laxity and tear trough (Shadowing effect)}

Shadowing due to the skin laxity and tear trough is another cause of $\mathrm{POH}$. These are the result from a combination of advancing age and chronic photodamage. Over time, collagen and elastin in the thin tissue of the eyelids and periorbital skin undergo degeneration. ${ }^{11}$ In addition, the damaged epidermis releases collagenases also contribute to degeneration of collagen and therefore the skin laxity confers a shadow effect on the lower eyelids. The tear trough is a depression centered over the medial side of the inferior orbital rim. It deepens as the patient ages because infraorbital fat is displaced anteriorly due to the loss of periorbital subcutaneous fat with thinning of the skin over the orbital rim ligament that confers hollowness to the orbital rim area ${ }^{9}$ along with pseudoherniation of the infraorbital fat that accentuate the shadowing effects. This shadowing effects is light dependent, often masked with the use of direct flash photography. ${ }^{12}$

\section{Other causes}

Drugs: Ocular hypotensive eye drops drugs as prostaglandin analogues (latanoprost and bimatoprost, travoprost etc.) can also cause periorbital hyperpigmentation after 3-6 months of treatment. ${ }^{13}$ The possible mechanisms of the pigmentation are 
increased melanogenesis in dermal melanocytes and increased transfer of melanin to basal epidermis, though rare, but an acquired orbital lipodystrophy may develop owing to the potent antiandrogenic effects of prostaglandin $\mathrm{F} 2 .{ }^{14}$

Underlying systemic, metabolic, hormonal disorders: It has been found that certain underlying systemic, metabolic, hormonal diseases, nutritional deficiencies may lead to pigmentation of the periorbital area, however no substantial evidenced in the literature. ${ }^{15}$

Life style factors: Some life style factors such as sleep disorders, stress, alcohol consumption, smoking, frequent cosmetic use, frequent eye rubbing and lack of correction for errors of refraction like myopia are also implicated to $\mathrm{POH}$ although not clinically substantiated. ${ }^{16}$

\section{Clinical Features}

Clinically, $\mathrm{POH}$ is characterized by light to darkcolored, brownish black pigmentation surrounding the eyelids. It may present as a curved band of brownish to black pigmentation on the skin of the lower eyelids approximating the shape of the orbital rim with frequent involvement of the upper eyelids or it may present as irregular patches of brownish or grey pigmentation on the skin on the upper, lower or both eyelids with features of lichenification, accentuation of skin creases, and eczematous papules or patches in the surrounding areas. Sometimes it presents as erythema predominantly involving the inner aspect of the lower eyelids, with prominent capillaries or telangiectasia (capillaries) or the presence of bluish discoloration of the lower eyelid and visible bluish veins that becomes more prominent when the overlying skin is stretched. ${ }^{17}$

\section{Evaluation}

The diagnosis of periorbital hyperpigmentation is mainly clinically, however, a thorough history and clinical assessment is necessary to identify the contributing etiologic factors and thus provide the targeting therapies for an individual patient of $\mathrm{POH}$.

A detailed history including duration of the condition, family history, history of atopy or drug intake, associated faulty habit or lifestyle, use of cosmetics, precipitating factor such as photosensitivity, allergies, seasonal variations, presence of associated other cutaneous disorder in other areas of the face and presence of any concomitant illness such as anemia, gastrointestinal diseases, hepato-biliary diseases, renal diseases, thyroid diseases, etc. should first be elicited.
The cutaneous examination should be evaluated to detect the involvement of eyelids, extend beyond the periorbital region, color of hyperpigmentation, presence of any dermatological disease or scar in the periorbital region, presence of any visible bulging, skin laxity, tear trough, superficial visible vasculature (i.e., capillaries or veins) in the infraorbital region, pallor in palpebral conjunctiva, presence of pigmentation in other areas after washing the face with soap and water.

The patient must be examined under the direct light to identify the $\mathrm{POH}$ due to shadow effect. Tear trough gets accentuation with hard light from direct flash digital photography while masking with 45-degree soft light from a strobe light source. The medial and central aspects of the tear trough may be accentuated with an upward gaze, whereas the lateral border may be accentuated with an upward outward gaze contralaterally. ${ }^{18}$

If possible, ask the patient to provide the prior photographs that can help to distinguish the normal anatomic variation from age-related changes.

\section{Eyelid stretch test}

Eye lid stretch test or manual stretching of the lower eyelid skin can help to differentiate between true pigmentation and shadowing effect. Although the former retains its appearance with stretching, the latter improves or resolves entirely. if the violaceous hyperpigmentation on manual stretching of the lower eyelids is worsen, then it is because of subdermal vascularity. ${ }^{14}$

\section{Wood's lamp examination}

Sometimes, there may be a problem in differentiating brown or blue purple hue in mixed type of $\mathrm{POH}$ because the blue hue may be missed at first site due to hyperpigmented background that's when wood's lamp examination is done to differentiate between the epidermal and dermal pigmentation. ${ }^{19}$ The variations in epidermal pigmentation become more apparent under Wood's light. For dermal pigmentation, this contrast is less pronounced ${ }^{2}$. The Wood's lamp is also assisted in the differentiation of the pigmented $(\mathrm{P})$ and mixed (M) types from the vascular type (V) of $\mathrm{POH}$. However, there is no change in vascular, structural and vascular-structural of mixed type. ${ }^{21}$

Other tests that are useful in the diagnosis of periorbital hyperpigmentation are dermatoscopy, histopathology and imaging.

Dermatoscopy: It is a noninvasive diagnostic technique 
for the in vivo observation of pigmented skin lesion allowing a better visualization of surface and subsurface structures and being easy and feasible to use. It can be used to differentiate the type of $\mathrm{POH}$ whenever there is doubt while examining with naked eyes. The dermatoscopic findings of $\mathrm{POH}$ are- a) Vascular type: diffuse erythema pattern or multiple thin blood vessels or diffuse vascular network, b) Pigmented type: a pattern of multiple dots with different sizes and colors or a diffuse network of pigments and c) Mixed type: Combination of vascular and mixed type. ${ }^{21}$

Histopathology: Histopathologic evaluation of epidermal characteristic, increase melanocytes pigmentation in the epidermis itself and increase in dermal melanocytes or pigmentation is the gold standard for a better understanding of the underlying etiopathogenesis. ${ }^{22}$ However, it has certain limitation in the form of development of scar at the site of the biopsy, which may be a concern for the patient.

Imaging: imaging with VISIA system (Canfield Scientific, Inc, Fairfield, NJ) can highlight blood vessels and pigmentation with UV light and cross-polarized flash photography

Digital photography: Standardized, high-quality pretreatment and posttreatment digital photography with appropriate light is needed for the assessment of the treatment response.

\section{Clinical Pattern Classification of POH}

The classification of different patterns and severity score of $\mathrm{POH}$ are important in introducing the therapeutic modalities on the basis of $\mathrm{POH}$ type, as different types of $\mathrm{POH}$ respond to different types of treatment.

Ranu et al in 2011 classified Periorbital hyperpigmentation on the basis of four parameters: Color pattern, boundaries, skin texture, associated skin disorders on and around the eyelids in order to determine the primary cause of $\mathrm{POH} .{ }^{17}$

a. Constitutional - The presence of a curved band of brownish to black pigmentation on the skin of the lower eyelids approximating the shape of the orbital rim with frequent involvement of the upper eyelids.

b. Post inflammatory - Presence of irregular patches of brownish or grey pigmentation on the skin on the upper, lower or both eyelids with features of accentuation of skin creases, lichenification and eczematous papules or patches in the surrounding areas. Personal and/or family history of atopy may or may not be present.

c. Vascular - Presence of erythema predominantly involving the inner aspect of the lower eyelids, with prominent capillaries or telangiectasia (capillaries) or the presence of bluish discoloration of the lower eyelid and visible bluish veins that becomes more prominent when the overlying skin is stretched. This type of dark circle appears to be due to a combination of transparency of the overlying skin and dermal vascularity.

d. Shadow effect - Presence of a dark shadow under an overhanging tarsal muscle, eye bags, or the presence of a deep tear trough over the medial aspect of the inferior orbital rim, which disappear with direct light.

e. Others-POH from other causes, including anemia, hormonal disturbances, nutritional deficiencies, acanthosis nigricans, skin laxity, associated chronic illness, habits, etc.

Recently Huang et ${ }^{20}$ proposed a classification on the basis of clinical pattern of pigmentation and vasculature as the hue of $\mathrm{POH}$ potentially indicates its cause and pathogenesis and can be well practiced in clinical consultation. The Periorbital hyperpigmentation is classified into pigmented type (brown color), vascular type (blue/pink/purple color with or without periorbital puffiness), structural type (skin color structural shadows formed by facial anatomic surface contours due to loss of fat or soft tissue volume with bony prominence that disappear after illuminating with front light), and mixed type (combines two or three of the above appearances). The mixed type of dark eye circle includes four subtypes as pigmentedvascular (PV), pigmented-structural (PS), vascularstructural (VS), and a combination of the three (PVS).

\section{POH Severity Assessment}

Severity score of $\mathrm{POH}$ is done in comparison to the surrounding skin and has been scored as 0 - skin colour comparable to other facial skin areas, 1 - faint pigmentation of infraorbital fold, 2 - pigmentation more pronounced, 3 - deep dark color, all four lids involved and 4 - grade $3+$ pigmentation spreading beyond infraorbital fold. ${ }^{15}$

\section{Association of other Pigmentary Conditions with $\mathrm{POH}$}

There are various conditions, which may be associated with periorbital hyperpigmentation such as pigmentary line of demarcation, Acanthosis nigricans, melasma, 
Erythema dyschromicum perstans, fixed drug eruption, ecchymosis, amyloidosis, dermatomyositis etc. Therefore, these underlying health issue must be evaluated prior to formulating a treatment plan for the $\mathrm{POH}$.

\section{Treatment}

Despite a great number of available medications and therapies to attenuate periorbital hyperpigmentation, there is lack of evidence-based studies to support their use. ${ }^{1}$ Periorbital hyperpigmentation is often refractory to the treatment. Therefore, the patient may be treated either as monotherapy or in combination therapy targeting the contributing factors. These include bleaching creams, topical retinoic acid, chemical peels, platelet rich plasma therapy, lasers and light therapy, soft tissue augmentation by autologous fat injection and hyaluronic acid soft tissue fillers, micro-focused ultrasound therapy and surgery.

\section{General measures}

Sun protection is a cornerstone of therapy. It is essential by avoiding peak hours of sunlight (in the tropics, between 11 AM 4 PM), using shady side for activities and making use of sunshades like parasols and broad brimmed hats. Use of opaque sunscreens containing zinc oxide, $10 \%$ (and SPF of 30 ) have the dual benefit of camouflaging and preventing photoinduced darkening.

Cosmetic camouflage may be used during treatment to improve the quality of life.

\section{Topical Applications}

Topically applied products are the most suitable treatment to start with for the majority of patients. ${ }^{23}$ These have been considered to improve the blood circulation and/or reduce melanin. Bleaching agents may be used as a monotherapy or combination therapy with other procedures. The most bleaching agents inhibit tyrosinase activity, inhibit DNA synthesis in hyperactive melanocytes, reduce the epidermal content of melanin, and thickening of the epidermis. ${ }^{24}$

The various topical bleaching agents are hydroquinone, kojic acid, a triple combination, azelaic acid, arbutin, topical vitamin C. Out of these topical agents the most widely used is hydroquinone, used in a strength of $2 \%$ to $6 \%$ with the effect of treatment being evident after 5 to 7 months of treatment. Sometimes, it is associated with fewer side-effects like mild skin irritation, itching, transient hypochromia, post-inflammatory hyperpigmentation.
Triple combination (hydroquinone, tretinoin and steroid), though available in the market in various combination and is being used for the treatment of melasma and other pigmentary conditions, there is no evident based study on its use in the $\mathrm{POH}$.

Kojic acid is a natural occurring fungal derivative produced by aspergillus species and penicillium species, has been tried in treating $\mathrm{POH}$ anecdotally in a concentration ranging from 1 to $4 \%$ and has been found to be effective with side-effects like erythema and contact dermatitis though there are no studies yet.

Azelaic acid was initially developed for treating acne but because of its effect on tyrosinase and further with no development of leukoderma and exogenous ochronosis on prolonged use, it has been used for facial post-inflammatory hyperpigmentation and thus it is a potentially promising agent for periocular hyperpigmentation due to post-inflammatory hyperpigmentation.

Arbutin is an extract of leaves from bearberry shrub and cranberry, pear or blueberry leaves has been found effective in treating melasma. So, it can be used in other hyperpigmentation including $\mathrm{POH}$ but with caution as high doses may lead to hyperpigmentation. It is available in a concentration of $3 \%$.

Topical vitamin $\mathrm{C}$ is an antioxidant that scavenges free oxygen radicals in aqueous compartment which triggers melanogenesis and promotes collagen production and conceals color of blood stasis, which improves the appearance of $\mathrm{POH}$. But as ascorbic acid is unstable, esterified derivatives in the form of L-ascorbic acid, 6-palmitate and magnesium ascorbyl phosphate are used. ${ }^{2}$ Ohshima and colleague ${ }^{25}$ studied 14 subjects with dark circles of the lower eyelids and applied sodium ascorbate $10 \%$ or ascorbic acid glucoside $10 \%$ in a split faced manner for 6 months. They conclude that sodium ascorbate may improve dark circles by thickening the eyelid dermis and concealing dark coloration due to congested blood but there was no change in the melanin index.

\section{Chemical peels}

Chemical peels may be used alone or in combination with topical bleaching agents. Glycolic acid is the most widely used alpha hydroxy acid for chemical peeling. Glycolic acid $20 \%$ can also be used for periorbital hyperpigmentation however higher concentration should be avoided to remove melanin from dermis. This may lead to dyspigmentation and scarring as the skin is thin in this area. 
Lactic acid $15 \%$ has been used in periorbital hyperpigmentation in combination with trichloroacetic acid (TCA) $3.75 \%$ every week for four treatments and it was found that almost all the patients showed significant esthetic improvement. ${ }^{26}$ For treatment of $\mathrm{POH}$ in medium to darker skin, it is best to extend the peel to the entire face to avoid post-peel demarcation. For optimal outcome, pretreatment with a tretinoin and hydroquinone bleaching agent for 2 to 4 weeks is recommended before undergoing a chemical peel. The most disturbing side effect of chemical peels can be post-inflammatory hyperpigmentation. This may be minimized with the help of priming agents, such as hydroquinone and tretinoin.

\section{Lasers}

Periorbital hyperpigmentation has been successfully treated with various lasers that target pigment, vascularity and skin laxity and tear trough.

\section{Q-switched lasers}

Q-switched lasers with nanosecond (and recently picosecond) pulse durations and wavelengths within the absorption range of melanin are useful for targeting the pigmentation in $\mathrm{POH}$. The typical clinical endpoint of these treatments is immediate lesion whitening without pinpoint bleeding. Lower energy settings should be used initially to minimize the occurrence of $\mathrm{PIH}^{3}$

\section{$Q$ switched ruby lasers (QSRL)}

Rapid delivery of high-intensity energy at the 694-nm wavelength of QSRLS is moderately absorbed by melanin but poorly absorbed by hemoglobin, which disrupts melanosomes within keratinocytes, melanocytes, and melanophages and is considered as first-line treatment for both dermal and epidermal pigmentation in Fitzpatrick skin types I-II.

QRSL treatment is performed with 2 to $4 \mathrm{~J} / \mathrm{cm}^{2}$ using a 5-mm spot size (or varied accordingly) at $1.5 \mathrm{~Hz}$. Watanabe et $\mathrm{al}^{27}$ showed good response in infraorbital hyperpigmentation after 1 to 5 treatments sessions with the $Q$ switched ruby laser $(694 \mathrm{~nm})$. Combining Q switched ruby laser $(694 \mathrm{~nm})$ with a bleaching agent containing $0.1 \%$ tretinoin and $5 \%$ hydroquinone has also led to significant improvement in this site. The purpose of this treatment is to improve epidermal pigmentation by accelerated discharge of epidermal melanin by tretinoin and suppressing new epidermal melanogenesis by hydroquinone cream. ${ }^{28}$

\section{$Q$ switched alexandrite lasers (QSAL)}

The Q-switched alexandrite laser (755-nm wavelength) penetrates deeper with a lower absorption coefficient for melanin and is emitted over a longer pulse duration (50-70 ns) than that of QSRL, which may serve to decrease adverse events (eg, $\mathrm{PIH}$ ) in dark-skinned patients as a result of milder melanosomal heating. Fitzpatrick skin types of IV or lower are performed with 3- to $5-\mathrm{mm}$ spot sizes and 4 to $8 \mathrm{~J} / \mathrm{cm}^{2}$. Lower fluences may lead to equal efficacy with decreased $\mathrm{PIH} .{ }^{29}$

\section{$Q$ switched Nd-YAG lasers}

Q switched Nd-YAG laser with a wavelength of 1064 $\mathrm{nm}$ allow for much deeper energy penetration and minimal melanin absorption compared with QSRL or QSAL. Therefore, Fitzpatrick skin types $\mathrm{V}$ and $\mathrm{VI}$ can be treated with minimal risk of posttreatment dyspigmentation. In a study conducted by Xu et $\mathrm{al}^{30}$ in thirty Chinese female patients with under-eye circles, 8 low-fluence treatments (3.5-mm spot size, $4.2 \mathrm{~J} /$ $\mathrm{cm}^{2}, 2$ passes) at 3- to 4-day intervals showed a mean global improvement of $50 \%$ to $75 \%$ at 3 and 6 months, and $93.3 \%$ subjects reported good to excellent results without significant adverse events.

\section{Pulsed-Dye Lasers}

Pulsed-dye lasers (585 and $595 \mathrm{~nm}$ wavelengths and pulse widths less than or equal to $40 \mathrm{~ms}$ ) allow for selective photothermolysis of larger, deeper ectatic vessels and a far greater purpuric threshold. ${ }^{31}$ Dark skinned patients should be treated with longer pulse durations and lower fluences. Treatment endpoint is immediate vessel spasm and transient purpura indicative of intravascular coagulation. Care should be taken when using cryogen cooling, because the cryogen is likely to enhance $\mathrm{PIH}$.

Pulse stacking and multiple passes at subpurpuric fluences with adequate epidermal protection (cryogen or convection cooling) lead to significant improvement in vessel clearance without added adverse events, but multiple treatment sessions may be needed. Superficial telangiectasias are treated with pulse durations and fluences of $6 \mathrm{~ms}$ and 7 to $9 \mathrm{~J} / \mathrm{cm}^{2}$ (less than $0.6 \mathrm{~mm}$ ) or $10 \mathrm{~ms}$ and 8 to $12 \mathrm{~J} / \mathrm{cm}^{2}$ (greater than $0.6 \mathrm{~mm}$ ) using a 7-mm spot size, with marginally overlapping pulses. Thicker facial vessels require 20 to $40 \mathrm{~ms}$ pulse widths and sub-purpuric fluences as high as 13 to $15 \mathrm{~J} / \mathrm{cm}^{2}$. One to 3 sessions at 4 - to 8 -week intervals are often needed.

\section{Long-pulsed Nd-YAG Lasers}

Long-pulsed $1064 \mathrm{~nm} \mathrm{Nd:YAG} \mathrm{lasers} \mathrm{are} \mathrm{ideal} \mathrm{for} \mathrm{the}$ treatment of larger, deeply situated facial vessels (eg, reticular veins) due to the more penetration of laser energy at this wavelength. Fitzpatrick skin types $\mathrm{V}$ and $\mathrm{VI}$ can be treated with low risk of epidermal injury 
because of the low absorption coefficient for melanin at $1064 \mathrm{~nm}$. Treatment parameters for periorbital veins are based directly on vessel size and a 3.5-mm (range, 2 to 10 ) spot size; $1-\mathrm{mm}$ reticular veins are treated with a 25-ms pulse duration and fluences of 160 to $190 \mathrm{~J} /$ $\mathrm{cm}^{2}$, whereas 1- to 3-mm veins require up to $50 \mathrm{~ms}$ and 190 to $210 \mathrm{~J} / \mathrm{cm}^{2}$. Vessel spasm or thrombosis is the endpoint of treatment, demonstrated by immediate vessel blanching or darkening.

In a study, twenty-six Chinese subjects with undereye dark circles having prominent reticular veins (1.0 to $2.5 \mathrm{~mm}$ ) were treated with a 6-mm spot size, 120 to $140 \mathrm{~J} / \mathrm{cm}^{2}$ fluence, and 6- to $10-\mathrm{ms}$ double-pulsing with a 20-ms delay at monthly sessions using a contact cooled long-pulsed Nd:YAG laser. ${ }^{32}$ At 12 -month followup, all subjects were found to have complete vessel resolution. A retrospective study confirmed nearly $100 \%$ subjective and objective improvement after 1 to 2 sessions with appropriate settings.

\section{Ablative Traditional and Fractional Lasers Traditional Ablative Lasers}

Pulsed $\mathrm{CO}_{2}$ and erbium: YAG lasers preferentially absorbed by water, leading to confluent epidermal vaporization and thermal damage of the superficial dermis, leads to contraction and denaturation of collagen. Alster and Bellew ${ }^{33}$ treated 67 patients with dermatochalasia and periorbital rhytides using $\mathrm{CO}_{2}$ laser resurfacing and found a significant improvement.

\section{Ablative Fractional Lasers}

Fractionated lasers create columnar microthermal treatment zones, which leave up to $95 \%$ of the cutaneous surface intact and thus provide an endogenous reservoir for rapid healing and barrier to infection. Significant improvement in deep wrinkles, fine lines, texture irregularity, laxity, and dyschromia can be achieved with a single treatment.

Tierney and colleagues ${ }^{34}$ treated twenty-five subjects with lower eyelid laxity with 2 to 3 sessions of ablative fractional resurfacing (AFR) using a $\mathrm{CO}_{2}$ laser $(25 \%$ coverage, $30 \mathrm{~W}, 1-\mathrm{ms}$ dwell time). A mean improvement of $65.3 \%$ and $62.1 \%$ in laxity and rhytides, respectively were found at 6-month follow-up.

However, ablative lasers are associated with greater discomfort, side effects, a weeklong downtime, and an intense postoperative care.

\section{Non-ablative Fractional Lasers (NAFR)}

NAFR laser causes dermal coagulation necrosis limited to microthermal treatment zones eventuating in collagen remodeling but spares the overlying epidermis, leading to rapid recovery and reduced adverse events after the procedure A study by Sukal and colleagues ${ }^{35}$ found $50 \%$ to $100 \%$ improvement in eyelid skin tightening in $55 \%$ of subjects after 3 to 7 sessions ( 17 to $20 \mathrm{~mJ}, 500$ to 750 microthermal treatment zones per $\mathrm{cm}^{2}$ ) with a $1550-\mathrm{nm}$ NAFR.

\section{Intense Pulsed Light (IPL)}

IPL can be used for periorbital pigmentation and vascularity. For telangiectasia and reticular veins in infraorbital area, minimal pressure should be applied against the skin with the hand piece to avoid compression of target vessels. A typical patient requires 1 to 3 sessions to achieve significant improvement, with subsequent semiannual maintenance treatments.

Inappropriate use of lasers and light in periorbital area may result in eye problems, including blindness, dryness and photophobia. Therefore, safety should be emphasized when treating periocular area with lasers and light by the use of proper eyewear (eye shields). ${ }^{1}$

\section{Soft tissue augmentation by autologous fat transplantation and soft tissue filer}

The violaceous appearance of $\mathrm{POH}$ which is due to little or no subcutaneous fat is treated by using autologous fat transplantation or soft tissue filler.

\section{Autologous fat transplantation}

It is a technique by which fat tissues are removed from other parts of the body, usually thigh, buttock, belly by liposuction and then the tissues are processed into liquid and injected into the lower eyelid skin overlying the orbicularis oculi muscle. Roh and Chung ${ }^{1}$ treated 10 patients with infraorbital dark circles due to increased vascularity and translucency of the skin by at least one autologous fat transplantation, and followup evaluations was done at least 3 months after the last treatment. These patients showed an average of $78 \%$ improvement.

\section{Fillers}

Hyaluronic acid gel is used as a filler for threedimensional reshaping of periorbital complex. The ease of use, minimal incidence of complications and lack of downtime associated with this product makes it nearly ideal for treating infraorbital volume loss. Though, patient satisfaction is high, some patients may get darker pigmentation after hyaluronic acid gel.

Bosniak et al, ${ }^{36}$ treated 12 patients with $\mathrm{POH}$, tear trough deformity, or prominent nasojugal groove with the hyaluronic acid push technique. All patients 
experienced immediate improvement after the procedure.

\section{Platelet-rich plasma}

Platelet rich plasma is a therapy using blood with high levels of platelet containing growth factors, esp. for acceleration in healing and regeneration. Recently. platelet-rich plasma has been used in treating dark circles due to tear trough deformity and wrinkles. A single session with intradermal injections of $1.5 \mathrm{ml}$ platelet-rich plasma was given into the tear trough area and wrinkles of crow's feet. The effect was compared to three months after treatment with baseline. The improvement in infraorbital color homogeneity was statistically significant. ${ }^{37}$

\section{Micro-focused ultrasound}

Micro-focused (or intense focused) ultrasound corrects mild to moderate skin and soft tissue laxity by short duration ( 25 to $50 \mathrm{~ms}$ ) pulses of transcutaneous ultrasound energy with frequencies in the megahertz $(\mathrm{MHz})$ range to create precise areas of spatially focused, chromophore-independent thermal coagulative damage, sparing intervening tissues or overlying skin. ${ }^{38}$ A single treatment session of intense focused ultrasound for infraorbital laxity treatment has shown increase reticular dermal collagen and thickness. ${ }^{39}$

\section{Surgery}

Blepharoplasty helps in eliminating dark circles caused by shadows that are cast by fat deposits or excess skin. Transconjunctival blepharoplasty is a better approach than transcutaneous blepharoplasty so that no external visible scar is created. Targeting the contributing causes for infraorbital dark circles, the combination of transconjunctival blepharoplasty and deep-depth phenol chemical peel for pseudoherniation of the

\section{References}

1. Roh MR, Chung KY. Infraorbital dark circles: definition, causes, and treatment options. Dermatol Surg. 2009; 35:1163-71. https://doi. org/10.1111/j.1524-4725.2009.01213.x

2. Sarkar R, Ranjan R, Garg S, et al. Periorbital Hyperpigmentation: A Comprehensive Review. J Clin Aeasthet Dermatol. 2016; 9: 49-55.

3. Freitag FM, Cestari TF. What causes dark circles under the eyes? J Cosmet Dermatol. 2007; 6: 211-5. https://doi.org/10.1111/j.14732165.2007.00324.x orbital fat and treatment of hyperpigmentation of the skin have found better outcome. ${ }^{40}$

\section{Others}

Carboxytherapy: Carboxytherapy employs injections to infuse gaseous carbon dioxide below the skin into subcutaneous tissue through a needle and Paolo et $\mathrm{al}^{41}$ found a significant improvement in fine lines and $\mathrm{POH}$ after the use of subcutaneous injections of carbon dioxide once a week for seven weeks in the periorbital area.

Normobaric oxygen therapy: Recently oxygen was administered via a nasal cannula at a rate of $1 \mathrm{lt} / \mathrm{min}$, for 1 hour twice weekly for 3 weeks. The major clinical changes following treatment included lightening of the color and reduction in size of darkened area and decrease in pigmentation and erythema on dermascopy. ${ }^{42}$

\section{Conclusion}

$\mathrm{POH}$ is a common benign facial cosmetic problem with multiple factorial etiology. Though, there are a number of treatment options available for periorbital hyperpigmentation, there is a lack of evidencebased studies for the treatment. It is important to identify the pattern of $\mathrm{POH}$ to adapt the treatment modalities in the individual patient. Pigmented $\mathrm{POH}$ may be effectively treated with bleaching agents (hydroquinone, a triple combination, kojic acid etc.), chemical peels, pigmented lasers, whereas vascular $\mathrm{POH}$ may be treated with topical vitamin $\mathrm{K}$ products, vascular lasers and IPL. Structural POH may be treated with Platelet rich plasma, fractional lasers, fillers, autologous fat transplantation, blepharoplasty and mixed $\mathrm{POH}$ may be treated with the combination of the above-mentioned modalities to improve the quality of life of the patients.

4. Yaar M, Gilchrest BA. Skin aging: Postulated mechanisms and consequent changes in structure and function. Clin Geriatr Med. 2001; 17: 617-30. https://doi.org/10.1016/S0749-0690(05)70089-6

5. Gendler EC. Treatment of periorbital hyperpigmentation. Aesthetic Surg J. 2005;25(6):618-24. https://doi.org/10.1016/j. asj.2005.09.018

6. Roberts WE. Periorbital hyperpigmentation: review of etiology, medical evaluation, and aesthetic treatment. J Drugs Dermatol. 2014;13(4):472-82. 
7. Sardana K, Rajpal M, Garg V, et al. Periorbital hyperpigmentation mimicking fixed drug eruption: A rare presentation of erythema dyschromicum perstans in a paediatric patient. J Eur Acad Dermatol Venereol. 2006; 20: 1381-3. https:// doi.org/10.1111/j.1468-3083.2006.01735.x

8. Gathers RC. Periorbital hypermelanosis. In: Paul KA, editor. Dermatology for Skin of Color 1st ed. New York: McGraw Hill; 2009. pp341-3.

9. Goldberg RA, McCann JD, Fiaschetti D, et al. What causes eyelid bags? Analyses of 144 consecutive patients. Plast Reconstr Surg. 2005; 115:1395-402. https://doi.org/10.1097/01. PRS.0000157016.49072.61

10. Taskin B. Periocular pigmentation: Overcoming the difficulties. J Pigmentary Disorders. 2015; 2:13.

11. Kurban RS, Bhawan J. Histologic changes in skin associated with aging. J Dermatol Surg Oncol. 1990;16: 908-14. https://doi. org/10.1111/j.1524-4725.1990.tb01554.x

12. Kane MA. Treatment of tear trough deformity and lower lid bowing with injectable hyaluronic acid. Aesthetic Plast Surg. 2005;.29:363-7.

13. Doshi M, Edward DP, Osmanovic S. Clinical course of bimatoprost induced periocular skin changes in Caucasians. Ophthalmology. 2006; 113:1961-7. https://doi.org/10.1016/j.ophtha.2006.05.041

14. Friedmann DP, Goldman MP. Dark circles: etiology and management Options. Clin Plast Surg. 2015; 42: 33-50. https://doi.org/10.1016/j. cps.2014.08.007

15. Sheth PB, Shah HA, Dave JN. Periorbital hyperpigmentation: a study of its prevalence, common causative factors and its association with personal habits and other disorders. Indian J Dermatol. 2014; 59:151-7. https://doi. org/10.4103/0019-5154.127675

16. Robert WE. Periorbital hyperpigmentation: Review of etiology, medical evaluation, and aesthtetic treatment. J Drugs Dermatol. 2014;13: 472-82.

17. Ranu H, Thng S, Goh BK, et al. Periorbital hyperpigmentation in Asians: an epidemiologic study and a proposed classification. Dermatol Surg. 2011; 37:1297-1303. https://doi. org/10.1111/j.1524-4725.2011.02065.x

18. Hirmand $\mathrm{H}$. Anatomy and nonsurgical correction of the tear trough deformity. Plast Reconstr Surg. 2010; 125:699-708. https://doi.org/10.1097/ PRS.0b013e3181c82f90
19. Paraskevas LR, Halpern AC, Marghoob AA. Utility of the Wood's light: five cases from a pigmented lesion clinic. $\mathrm{Br} J$ Dermatol. 2005; 152:1039-44. https://doi.org/10.1111/j.13652133.2005.06346.x

20. Huang $\mathrm{YL}$, Chang SL, Ma L, et al. Clinical analysis and classification of dark eye circle. Int J Dermatol. 2014; 53:164-70. https://doi.org/10.1111/ j.1365-4632.2012.05701.x

21. Ahuja SK, Deshmukh AR, Khushalani SR. A study of dermatoscopic pattern of periorbital hypermelanosis. Pigment International. 2017; 4: 29-34. https://doi.org/10.4103/23495847.208295

22. Boruah D, Moorchung N, Vasudevan B, et al. Morphometric study of micro-vessels, epidermal characteristics and inflammation in psoriasis vulgaris with their correlations. Indian J Dermatol Venereol Leprol, 2013; 79: 216-23. https://doi. org/10.4103/0378-6323.107640

23. Alsaad SM, Mikhail M. Periocular hyperpigmentation: a review of etiology and current treatment options. J Drugs Dermatol. 2013; 12:154-7.

24. Sodhi, PK, Verma, L, Ratan, SK. Increased periocular pigmentation with ocular hypotensive lipid use in African Americans. Am J Ophthalmol. 2004; 137:783. https://doi.org/10.1016/S00029394(03)01513-7. https://doi.org/10.1016/ S0002-9394(03)01433-8

25. Ohshima $H$, Mizukoshi $K$, Oyobikawa $M$, et al. Effects of vitamin $C$ on dark circles of the lower eyelids: quantitative evaluation using image analysis and echogram. Skin Res Technol. 2009; 15:214-7. https://doi.org/10.1111/j.16000846.2009.00356.x

26. Vavouli, C, Katsambas, A, Gregoriou S, et al. Chemical peeling with trichloroacetic acid and lactic acid for infraorbital dark circles. J Cosmet Dermatol. 2003;12: 204-9. https://doi. org/10.1111/jocd.12044

27. Watanabe S, Nakai K, Ohnishi T. Condition known as "Dark Rings under the Eyes" in the Japanese population is a kind of dermal melanocytosis which can be successfully treated by Q-switched ruby laser. Dermatol Surg. 2006; 32:785-9. https://doi.org/10.1097/00042728-20060600000003. https://doi.org/10.1111/j.15244725.2006.32161.x

28. Mamosawa A, Kurita M, Ozaki M, et al. Combined therapy using Q-switched ruby laser and bleaching treatment with tretinoin and hydroquinone for 
periorbital skin hyperpigmentation in Asians. Plast Reconstr Surg. 2008; 121: 282-8. https://doi. org/10.1097/01.prs.0000293869.00522.ec

29. Wang CC, Chen CK. Effect of spot size and fluence on $\mathrm{Q}$-switched alexandrite laser treatment for pigmentation in Asians: a randomized, double blinded, split-face comparative trial. J Dermatolog Treat. 2012; 23:333-8. https://doi.org/10.3109/0 9546634.2011.560929

30. Xu TH, Yang ZH, Li YH, et al. Treatment of infraorbital dark circles using a low-fluence Q-switched 1,064-nm laser. Dermatol Surg. 2011; 37:797-803. https://doi.org/10.1111/j.15244725.2011.01956.x. https://doi.org/10.1111/ j.1524-4725.2011.01956..x

31. Goldman MP. Optimal management of facial telangiectasia. Am J Clin Dermatol. 2004; 5:423-34. https://doi.org/10.2165/00128071200405060-00007

32. Ma G, Lin XX, Hu XJ, et al. Treatment of venous infraorbital dark circles using a long-pulsed 1,064$\mathrm{nm}$ neodymium-doped yttrium aluminum garnet laser. Dermatol Surg. 2012; 38:1277-82. https:// doi.org/10.1111/j.1524-4725.2012.02457.x

33. Alster TS, Bellew SG. Improvement of dermatochalasis and periorbital rhytides with a high-energy pulsed CO laser: a retrospective study. Dermatol Surg. 2004; 30:483-7. https:// doi.org/10.1097/00042728-200404000$00001 . \quad$ https://doi.org/10.1111/j.15244725.2004.30160.x

34. Tierney EP, Hanke CW, Watkins L. Treatment of lower eyelid rhytids and laxity with ablative fractionated carbon-dioxide laser resurfacing: case series and review of the literature. J Am Acad Dermatol. 2011; 64:730-40. https://doi. org/10.1016/j.jaad.2010.04.023

35. Sukal SA, Chapas AM, Bernstein LJ, et al. Eyelid tightening and improved eyelid aperture through nonablative fractional resurfacing.
Dermatol Surg. 2008; 34:1454-8. https:// doi.org/10.1097/00042728-200811000$00003 . \quad$ https://doi.org/10.1111/j.15244725.2008.34308.x

36. Bosniak S, Sadick NS, Cantisano-Zilkha M, et al. The hyaluronic acid push technique for the nasojugal groove. Dermatol Surg. 2008; 34:127-31. https://doi.org/10.1097/00042728200801000-00028. https://doi.org/10.1111/ j.1524-4725.2007.34028.x

37. Mehryan P, Zartab H, Rajabi A, et al. Assessment of efficacy of platelet-rich plasma (PRP) on infraorbital dark circles and crow's feet wrinkles. J Cosmet Dermatol. 2014; 13:72-8. https://doi. org/10.1111/jocd.12072

38. Laubach HJ, Makin IR, Barthe PG, et al. Intense focused ultrasound: evaluation of a new treatment modality for precise microcoagulation within the skin. Dermatol Surg. 2008; 34:727-34. https://doi. org/10.1111/j.1524-4725.2008.34196.x. https:// doi.org/10.1097/00042728-200805000-00020

39. Suh DH, Oh YJ, Lee SJ, et al. An intense-focused ultrasound tightening for the treatment of infraorbital laxity. J Cosmet Laser Ther. 2012; 14:290-5. https://doi.org/10.3109/14764172.20 12.738912

40. Epstein JS. Management of infraorbital dark circles. A significant cosmetic concern. Arch Facial Plast Surg. 1994; 1:303-7. https://doi. org/10.1001/archfaci.1.4.303

41. Paolo F, Nefer F, Paola P, et al. Periorbital area rejuvenation using carbon dioxide therapy. J Cosmet Dermatol. 2012;11: 223-8. https://doi. org/10.1111/j.1473-2165.2012.00633.x

42. Mostafa WZ, Kadry DM, Mohamed EF. The effects of normobaric oxygen therapy on patients with periorbital darkening: An open, uncontrolled trial. Indian J Dermatol Venerol Leprol. 2015; 81: 427-9. https://doi.org/10.4103/0378-6323.159946. 